\title{
APPRAISAL OF AIRPORT ROUNDABOUT ON THE ANTOA ROAD, KUMASI-GHANA USING MICRO SIMULATION MODEL
}

\author{
A. Obiri-Yeboah ${ }^{1}$, E. K. Nyantakyi ${ }^{2}$, D. Pobee ${ }^{3}$, G. A. Mohammed ${ }^{4}$ \\ 1,2,3,4 Department of Civil Engineering, Kumasi Polytechnic, Kumasi-Ghana, \\ aanyar@yahoo.co.uk,emmanuelkwesinyantakyi@yahoo.com,drusspee@yahoo.com,gam1980sep@yahoo.com
}

\begin{abstract}
Roundabouts have become increasingly popular in recent years as an innovative operational and safety solution at both low volume and high volume intersections. Roundabouts have a number of advantages over traffic signals depending on the conditions. They reduce the severity of crashes since head-on and right-angle conflicts are nearly eliminated. They reduce through traffic speeds to provide a "calmer" roadway environment. This study appraised Airport roundabout on the Antoa Road in Kumasi, Ghana using micro simulation model. Traffic and geometric data were collected on the field. The analysis revealed that Airport roundabout was operating at a level of service $F$, which represented worst conditions. Signalized intersection with 4 approach lanes on the two principal arterials was proposed to control all the movements. Exclusive pedestrian phases were proposed to protect pedestrians.
\end{abstract}

Keywords: Appraisal, Airport roundabout, Capacity analysis, Antoa Road.

\section{INTRODUCTION}

As defined by the Federal Highway Administration [1], modern roundabouts are circular intersections with specific traffic control and design features. These features include yield control at entry, channelized approaches, and geometric approach curvature (deflection) to induce entering traffic to slow down to the design speed of the circulatory roadway. The crosswalks are set back from the intersection to minimize conflicts with turning vehicles. Roundabouts have characteristics that differentiate them from traffic circles, rotaries and traffic calming circles. Roundabouts have a proven safety record that is superior to other forms of traffic control [2 - 4]. The stretch of the Antoa road between the Airport roundabout and Buokrom area gets very congested especially during the morning and evening peak periods. Airport roundabout, which is on the Antoa road is a very busy roundabout and congested during the morning and evening peaks [5]. The activities of the washing bay around the airport roundabout also affect the smooth flow of traffic on the Airport-Buokrom section. There are virtually no sidewalks, resulting in pedestrians walking on the road, thereby exposing them to danger [5].

Previous studies on the performance of the roundabout attributed the congestion critical capacity and abuse to motorists and/or pedestrians. As part of the recommendations, the report proposed to improve upon the signalization and capacity at Airport roundabout. They recommended that if atgrade capacity cannot be obtained for the minimum requirements, then a grade separation scheme should be constructed at the roundabout. This could either be a flyover or an interchange [5].

These recommendations have not been implemented due to lack of funds and therefore long queues and frequent delays still persist during the morning and evening peaks of the day at the roundabout. It is in this light that this study was undertaken to appraise the capacity and performance of Airport roundabout in Kumasi to find out an effective way of resolving the traffic congestion problem.

\section{METHODOLOGY}

\subsection{Site Selection and Description}

Airport roundabout was selected based on its accident and safety records in the past and also the levels of congestion associated with the roundabout. Airport Roundabout Airport roundabout has five (5) legs with two (2) approach/entry and exit lanes on all legs, except the Manhyia/Kejetia and the Buokrom legs, which have one (1) approach/entry and exit lanes as shown in Fig 1. Airport roundabout is the intersection of two (2) Principal arterials and a local road, namely: Okomfo Anokye road - Principal Arterial, Antoa road Principal Arterial, and Airport road - Local road as shown in Fig. 1. 


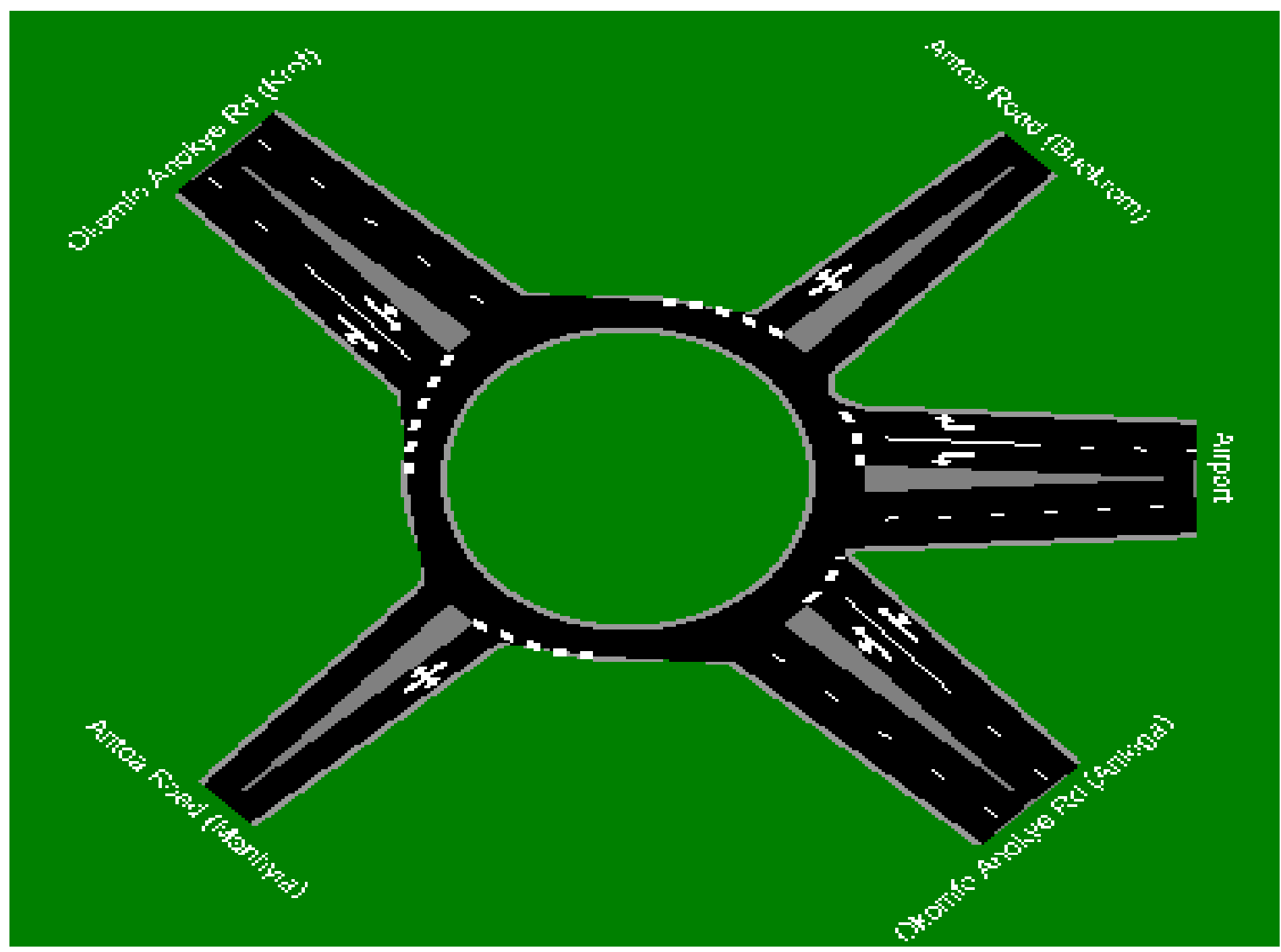

Fig-1: Geometry of Airport Roundabout; Source: BCEOM and ACON Report (2004)

\subsection{Study Area}

\subsubsection{Okomfo Anokye Road}

The Okomfo Anokye Road is a principal arterial running mostly in a North/South direction (Anloga Junction to Airport Roundabout) and mostly in an East/West direction (Airport roundabout to Suame Roundabout). It covers a distance of about $6.4 \mathrm{~km}$, (from Anloga Junction to Suame Roundabout). The road is a paved 2-lane dual carriageway (4-lane 2-way), over its entire stretch. The road forms part of the ring road and it provides a major vital link between the Western ByPass, Mampong Road and Offinso Road and the 24th February Road. This vital link serves as a bypass route, especially for the North/South travellers of the country.
The intersections along this road are the main cause of bottlenecks on the road. The intersection controls are not good enough and driver indiscipline also compounds it. The Adukrom intersection experiences illegal U-turns within the intersection, which creates hazardous conditions for oncoming traffic. There are lots of delay and conflicting movements at the Asokore Mampong Road/Aboabo Road intersection. This is due to the existing phasing plan/signal timings. There is a lot of diverted traffic joining the Asokore Mampong leg from Buokrom to avoid the congestion at the Airport Roundabout. This makes the approach volume heavy as against a small green time allotted to it. 


\subsubsection{Antoa Road}

The Antoa road is a principal arterial, which runs mostly in a North-South direction. The road covers an urban, (study) length of about $6 \mathrm{~km}$, (from Kejetia/Dr. Mensah to Buokrom area). The road is a single carriageway and it is paved throughout its entire length. The Antoa Road has a short oneway section, about 150 meters between "Dr. Mensah" and Odumase road intersection.

The Kejetia, (Dr Mensah) area is very congested as it is in the central business district. The road in this area is narrow with residences closely abutting it. The stretch of the Antoa road between the Airport roundabout and Buokrom area gets very congested especially during the morning and evening peak periods. A lot of diverted traffic from the Mampong road joins the Antoa road at the Buokrom Estate road intersection. The activities of the washing bay around the airport roundabout also affect the smooth flow of traffic on the Airport-Buokrom section. There are virtually no sidewalks, resulting in pedestrians walking on the road, thereby exposing them to danger.

\subsubsection{Airport Road}

The airport road leads to the Kumasi Airport.

\subsection{Basic Theoretical Background}

One of the oldest and most well known cases of the use of simulation in theoretical research is the "car-following" analysis based on the Generalized General Motors (GM) models. In these models a differential equation governs the movement of each vehicle in the platoon under analysis [6]. Car-following, like the intersection analysis, is one of the basic equations of traffic flow theory and simulation, and the analysis has been active after almost 40 years from the first trials [7].The car-following theory is of significance in microscopic traffic flow theory and has been widely applied in traffic safety analysis and traffic simulation $[8,9]$. There have been many car-following models in the past 60 years, and the models can be divided into two categories. One is developed from the viewpoint of traffic engineering and the other is based on statistical physics. From the perspective of traffic engineers [10], car-following models can be classified as stimulus-response models [11,12], safety distance models [13], psycho-physical models [14], and artificial intelligence models $[15,16]$.

The car-following theory is based on a key assumption that vehicles will travel in the center line of a lane, which is unrealistic, especially in developing countries. In these countries, poor road conditions, irregular driving discipline, unclear road markings, and different lane widths typically lead to non-lane-based car-following driving [17]. Heterogeneous traffic, characterized by diverse vehicles, changing composition, lack of lane discipline, etc., results in a very complex behavior and a non-lane-based driving in most Asian countries [18]. Therefore, it is difficult for every vehicle to be moving in the middle of the lane. Vehicles are positioned laterally within their lanes, and the off central-line effect results in lateral separations. However, to the limit of our knowledge, the effect of lateral separation in the car-following process has been ignored by the vast majority of models. A few researchers have contributed efforts on this matter. [17] first developed a car-following model with lateral discomfort. He improved a stopping distance based approach that was proposed by [13], and presented a new car-following model, taking into account lateral friction between vehicles.[19] proposed a non-lane-based car following model using a modified full-velocity difference model. All the above models have assumed that drivers are able to perceive distances, speeds, and accelerations. However, car-following behavior is a human process. It is difficult for a driver of the following vehicle to perceive minor lateral separation distances, and drivers may not have precise perception of speeds and distances, not to mention accelerations.

\subsubsection{Car-following Models}

The logic used to determine when and how much a car accelerates or decelerates is crucial to the accuracy of a microscopic simulation model. Most simulation models use variations on the GM model. Although it was developed in the 1950s and 1960s, it has remained the industry standard for describing car-following behavior and continues to be verified by empirical data. A variation on the GM model is the PITT car-following model, which is utilized in FRESIM. The GM family of models is perceived to be the most commonly used in microscopic traffic simulation models and are, therefore, the focus of this article.

\subsubsection{Generalized General Motors Models}

The first GM model modeled car-following is a stimulusresponse process in which the following vehicle attempts to maintain space headway. When the speed of a leading vehicle decreases relative to the following vehicle, the following vehicle reacts by decelerating. Conversely, the following vehicle accelerates when the relative speed of the leading vehicle increases. This process can be represented by the first GM model, given equation 1 .

$$
\ddot{\chi}_{F}=\alpha_{F} \times\left(\dot{\chi}_{L}(t)-\chi_{F}(t)\right)
$$

Where,

$\chi_{F \text { = acceleration of the following vehicle, }}$ 
$\bullet$

$$
\begin{aligned}
& \chi_{F=\text { speed of the following vehicle, }} \\
& \chi_{L=\text { speed of the leading vehicle, }} \\
& \alpha \mathrm{F} \quad=\text { sensitivity of the following vehicle, and } \\
& \mathrm{t}=\text { time. }
\end{aligned}
$$

\subsubsection{PITT Car-following Model}

FRESIM uses the PITT car-following model, which is expressed in terms of desired space headway, shown in the equation 2 .

$$
h_{s}(t)=L+m+k V_{2}+b k\left[V_{1}(t)-V_{2}(T)\right]^{2}
$$

Where,

hs $(\mathrm{t})=$ desired space headway at time $\mathrm{t}$,

$\mathrm{L}=$ length of leading vehicle,

$\mathrm{m}=$ minimum car-following distance (PITT constant),

$\mathrm{k}=$ car-following sensitivity factor for following vehicle,

$\mathrm{b}=$ relative sensitivity constant,

$\mathrm{v} 1(\mathrm{t})=$ speed of leading vehicle at time $\mathrm{t}$, and

$\mathrm{v} 2(\mathrm{t})=$ speed of following vehicle at time $\mathrm{t}$.

Equation above can be solved for the following vehicle's acceleration, given by the equation 3 .

$a=\frac{2 \times\left\lfloor x-y-L-m-V_{2}(K+T)-b k\left(V_{1}(t)-V_{2}(t)\right)^{2}\right\rfloor}{T^{2}+2 K T}$

Eq. (3)

Where,

$\mathrm{a}=$ the acceleration of the following vehicle,

$\mathrm{T}=$ the duration of the scanning interval,

$\mathrm{x}=$ position of the leading vehicle, and

$\mathrm{y}=$ position of the following vehicle.

\subsection{Algorithm on Synchro/SimTraffic Software}

Simulation is basically a dynamic representation of some part of the real world achieved by building a computer model and moving it through time. The results obtained from any simulation model will be as good as the model replicates the specific real world characteristics of interest to the analyst.

Once a vehicle is assigned performance and driver characteristics, its movement through the network is determined by three primary algorithms:

\subsubsection{Car Following}

This algorithm determines behavior and distribution of vehicles in traffic stream. Synchro varies headway with driver type, speed and link geometry whereas SimTraffic generates lower saturation flow rates.

\subsubsection{Lane Changing}

This is always one of the most temperamental features of simulation models. There are three types of lane-changing which includes

- Mandatory lane changes (e.g., a lane is obstructed or ends)

- Discretionary lane changes (e.g., passing)

- Positioning lane changes (e.g., putting themselves in the correct lane in order to make a turn): There is heavy queuing and this is a common problem for modeling positioning lane changes. Vehicles often passed back of queue before attempting lane change and their accuracy relates to degree of saturation and number of access points such as congested conditions which requires farther look ahead and densely-spaced access (i.e. short segments) which presents a problem.

\subsubsection{Gap Acceptance}

Gap acceptance affects driver behavior at unsignalized intersections, driveways (e.g., right-in-right-out) and rightturn-on-red (RTOR) movements. If default parameters are too aggressive, vehicle delay will be underestimated and there is serious implication for frontage roads. Conversely, parameters which are too conservative may indicate need for a signal when one isn't necessary. Gap acceptance parameters are network-wide in SimTraffic.

\subsubsection{Turning Movement Counts}

Data was collected manually at Airport roundabout because it was difficult getting good elevation observer positions. Turning movement counts were collected between 0600hours and 1800 hours during the morning and evening peak periods of the day at the roundabout. Two enumerators each were positioned on each leg of the approach to the roundabout. The number of vehicles entering and leaving the two principal arterials such as Antoa road and Okomfo Anokye road and the local road such as the Airport road were counted using the vehicle number plate method. All the Turning movement counts were conducted at $15 \mathrm{~min}$ intervals.

\subsubsection{Intersection Capacity Analysis for Suame}

\section{Roundabout}

The Department of Transport of the UK recommends a research carried out by the Transport and Road Research Laboratory (TRRL) that predicts an equation for the determination of the capacities of roundabouts. The predictive equation for entry capacity into the circulatory area was used for entry capacity determination and is given by equation 4 . 


$$
\mathrm{Qe}=\mathrm{K}^{*}\left(\mathrm{~F}-f_{c} \mathrm{Qc}\right) \quad \text { Eq. (4) }
$$

Where,

Qe is the entry flow into the circulatory area in passenger car units per hour (pcu/hr)

Qc is the flow in the circulatory area in conflict with the entry flow in passenger car units per hour ( $\mathrm{pcu} / \mathrm{hr}$ ).

$\mathrm{K}=1-0.00347(\phi-30)-0.978(1 / \mathrm{r}-0.05)$

$\mathrm{F}=303 \mathrm{X}_{2}$

$f_{c}=0.21 t D\left(1+0.2 X_{2}\right)$

$t D=1+0.5 /(1+M)$

$M=\exp [(D-60) / 10]$

$X_{2}=v+(e-v) /(1+2 S)$

$S=1.6(e-v) / l^{\prime}$

$e=$ entry width (metres) - measured from a point normal to the rear kerbside

$v=$ approach half-width: measured along a normal from a point in the approach stream from any entry flare

$l^{\prime}=$ average effective flare length: measured along a line drawn at right angles from the widest point of the entry flare
$S=$ sharpness of flare: indicates the rate at which extra width is developed within the entry flare

$D=$ inscribed circle diameter: the biggest circle that can be inscribed within the junction

$\phi=$ entry angle: measures the conflict angle between entering and circulating traffic

$r=$ entry radius: indicates the radius of curvature of the nearside kerb line on entry.

\subsubsection{Intersection Capacity Analysis}

The intersection Capacity analysis was performed using intersection capacity utilization (ICU) to determine the Level of service (LOS) at Suame roundabout. An initial analysis was performed for the existing rotary intersection to determine its performance. Once the ICU was fully calculated, the ICU LOS for the roundabout was subsequently calculated based on the criteria given by [20] Table -1 .

Table -1: Intersection Capacity Utilization LOS and Grading Criteria

\begin{tabular}{|l|l|l|}
\hline LOS & ICU $(\%)$ & Grading Criteria \\
\hline A & $\leq 55$ & Intersection has no congestion \\
\hline B & $55<$ ICU $<64$ & Intersection has very little congestion \\
\hline C & $64<\mathrm{ICU}<73$ & Intersection has no major congestion \\
\hline D & $73<\mathrm{ICU}<82$ & Intersection normally has no congestion \\
\hline E & $82<\mathrm{ICU}<91$ & Intersection is on the verge of congested conditions \\
\hline F & $91<\mathrm{ICU}<100$ & $\begin{array}{l}\text { Intersection is over capacity and likely experiences congestion periods of } \\
15 \text { to } 60 \text { consecutive minutes }\end{array}$ \\
\hline $\mathrm{G}$ & $1005<\mathrm{ICU}<109$ & $\begin{array}{l}\text { Intersection is } 9 \% \text { over capacity and experiences congestion periods of } 60 \\
\text { to } 120 \text { consecutive minutes } \\
\text { The intersection is } 9 \% \text { or greater over capacity and could experience } \\
\text { congestion periods of over } 120 \text { minutes per day. }\end{array}$ \\
\hline $\mathrm{H}$ & $>109 \%$ &
\end{tabular}

\section{RESULTS AND DISCUSSION}

\subsection{Turning Movement Counts}

Summary of total approach volume for each approach at Airport roundabout is shown in Table 2.

Table -2: Summary of Total Approach volume at Airport Roundabout

\begin{tabular}{ccccccc}
\hline Approaches & Anloga Jn & Krofrom & Kejetia & Buokrom & Airport & Total \\
\hline Anloga Jn & 0 & 1452 & 900 & 860 & 26 & 3238 \\
Krofrom & 1896 & 0 & 189 & 563 & 35 & 2683 \\
Kejetia & 989 & 198 & 0 & 960 & 33 & 2180 \\
Buokrom & 542 & 322 & 1230 & 0 & 13 & 2107 \\
Airport & 65 & 36 & 49 & 23 & 0 & 173 \\
Total & 3492 & 2008 & 2368 & 2406 & 107 & \\
\hline
\end{tabular}


Source: from study

It can be deduced from Table 2 that $31.2 \%$ of vehicles moved from Anloga Junction approach to the other approaches at Airport roundabout. This was followed by $25.8 \%$ of vehicles from Krofrom, $21.0 \%$ of vehicles from Kejetia whiles $20.3 \%$ of vehicles moved from Buokrom approach. Airport approach had $1.7 \%$ of vehicles moving to other approaches.

\subsection{Capacity Analysis}

Hourly flow rate for the approaches at Airport Roundabout is shown in Table 3

Table -3: Capacity calculations for Airport Roundabout Approaches Hourly flow rate (veh/hr)

\begin{tabular}{|c|c|}
\hline East Bound North (EBN), $\mathrm{V}_{1}$ & 1452 \\
\hline East Bound West (EBW), $\mathrm{V}_{2}$ & 900 \\
\hline East Bound South (EBS), $V_{3}$ & 860 \\
\hline East Bound South East (EBSE), $V_{4}$ & 26 \\
\hline West Bound North (WBN), $\mathrm{V}_{5}$ & 198 \\
\hline West Bound East (WBE), $\mathrm{V}_{6}$ & 989 \\
\hline West Bound South (WBS), $\mathrm{V}_{7}$ & 960 \\
\hline West Bound South East (WBSE), $V_{8}$ & 33 \\
\hline North Bound East (NBE), $V_{9}$ & 1896 \\
\hline North Bound West (NBW), $\mathrm{V}_{10}$ & 189 \\
\hline North Bound South (NBS), $\mathrm{V}_{11}$ & 563 \\
\hline North Bound South East (NBSE), $V_{12}$ & 35 \\
\hline South Bound North (SBN), $\mathrm{V}_{13}$ & 322 \\
\hline South Bound West (SBW), $\mathrm{V}_{14}$ & 1230 \\
\hline South Bound East (SBE), $V_{15}$ & 542 \\
\hline South Bound South East (SBSE), $V_{16}$ & 13 \\
\hline South East North (SEN), $\mathrm{V}_{17}$ & 36 \\
\hline South East West (SEW), $\mathrm{V}_{18}$ & 49 \\
\hline South East South (SES), $\mathrm{V}_{19}$ & 23 \\
\hline South East East (SEE), $\mathrm{V}_{20}$ & 65 \\
\hline
\end{tabular}

Source: from study

From Table 3, it was realized that North Bound East (NBE), $\mathrm{V}_{9}$ had the highest hourly flow rate of $1896 \mathrm{veh} / \mathrm{hr}$ at Airport roundabout. This meant that 1896 vehicles traversed the north bound east direction in an hour. Similarly, South Bound South
East (SBSE), $\mathrm{V}_{16}$ had the lowest hourly flow rate of $13 \mathrm{veh} / \mathrm{hr}$ meaning 13 vehicles traversed the South Bound South East direction within an hour.

Table - 4: Approach Flow at Airport Roundabout

\begin{tabular}{cc}
\hline Approach Flow (veh/hr) & Approach Volume, Va \\
\hline Va, $\mathrm{E}=\mathrm{V}_{1}+\mathrm{V}_{2}+\mathrm{V}_{3}+\mathrm{V}_{4}$ & 3238 \\
$\mathrm{Va}, \mathrm{W}=\mathrm{V}_{5}+\mathrm{V}_{6}+\mathrm{V}_{7}+\mathrm{V}_{8}$ & 2683 \\
$\mathrm{Va}, \mathrm{N}=\mathrm{V}_{9}+\mathrm{V}_{10}+\mathrm{V}_{11}+\mathrm{V}_{12}$ & 2180 \\
$\mathrm{Va}, \mathrm{S}=\mathrm{V}_{13}+\mathrm{V}_{14}+\mathrm{V}_{15}+\mathrm{V}_{16}$ & 2107 \\
$\mathrm{Va}, \mathrm{SE}=\mathrm{V}_{17}+\mathrm{V}_{18}+\mathrm{V}_{19}+\mathrm{V}_{20}$ & 173 \\
\hline
\end{tabular}

Source: from study 
Va,E approach had the highest approach flow of $3238 \mathrm{veh} / \mathrm{hr}$ as shown in Table 4 at Airport roundabout. This meant that 3238vehicles came from Va,E approach in an hour. $2683 \mathrm{veh} / \mathrm{hr}$ came from $\mathrm{Va}, \mathrm{W}$ approach, followed by $\mathrm{Va}, \mathrm{N}$ approach which had 2180veh/hr. Va,S approach gave $2107 \mathrm{veh} / \mathrm{hr}$ and $\mathrm{Va}, \mathrm{SE}$ approach gave a lowest approach volume of $173 \mathrm{veh} / \mathrm{hr}$.

Table -5: Circulating flows at Airport Roundabout

\begin{tabular}{lccc}
\hline \multicolumn{1}{c}{ Circulating Flow } & $\begin{array}{c}\text { Flow, Qc } \\
(\text { veh/hr })\end{array}$ & $\begin{array}{c}\text { Flow in pcu/hr } \\
(\mathrm{x} 1.1)\end{array}$ & $\begin{array}{c}\text { Factored Flow } \\
(\mathrm{x} 1.125)\end{array}$ \\
\hline $\mathrm{Vc}, \mathrm{E}=\mathrm{V}_{1}+\mathrm{V}_{2}+\mathrm{V}_{3}+\mathrm{V}_{4}$ & 1858 & 2044 & 2299 \\
$\mathrm{Vc}, \mathrm{W}=\mathrm{V}_{5}+\mathrm{V}_{6}+\mathrm{V}_{7}+\mathrm{V}_{8}$ & 3088 & 3397 & 3821 \\
$\mathrm{Vc}, \mathrm{N}=\mathrm{V}_{9}+\mathrm{V}_{10}+\mathrm{V}_{11}+\mathrm{V}_{12}$ & 3403 & 3743 & 4211 \\
$\mathrm{Vc}, \mathrm{S}=\mathrm{V}_{13}+\mathrm{V}_{14}+\mathrm{V}_{15}+\mathrm{V}_{16}$ & 3177 & 3495 & 3932 \\
$\mathrm{Vc}, \mathrm{SE}=\mathrm{V}_{17}+\mathrm{V}_{18}+\mathrm{V}_{19}+\mathrm{V}_{20}$ & 5177 & 5695 & 6407 \\
\hline
\end{tabular}

Vc,SE approach had the highest circulating flow of $5177 \mathrm{veh} / \mathrm{hr}$ at Airport roundabout, Vc,N approach which gave a circulating flow of $3403 \mathrm{veh} / \mathrm{hr}$ as shown in Table 5. Vc,S approach had a circulating flow of $3177 \mathrm{veh} / \mathrm{hr}$ with $\mathrm{Vc}, \mathrm{W}$ approach having the lowest circulation flow of $18585 \mathrm{veh} / \mathrm{hr}$. Similarly, in terms of flow in pcu, Vc,SE approach gave the highest flow of $5695 \mathrm{pcu} / \mathrm{hr}$ and the $\mathrm{Vc}, \mathrm{E}$ approach gave the least flow of $2044 \mathrm{pcu} / \mathrm{hr}$.

Entry capacity, circulating flow and reserve capacities for each approach at Airport roundabout is shown in Table 6.

Table -6: Entry capacity, circulating flow and reserve capacity for the approaches at Airport Roundabout

\begin{tabular}{lccccc}
\hline \multicolumn{1}{c}{ Parameters } & Airport & Krofrom & Anloga Jn & Buokrom & Kejetia \\
\hline Entry width, e & 7.7 & 7.7 & 7.7 & 7.7 & 7.7 \\
Approach Half width, v & 7 & 7 & 7 & 7 & 7 \\
Average Effective Flare & 15 & 15 & 15 & 15 & 15 \\
Length, l' & & & & & \\
Sharpness of Flare, S & 0.07467 & 0.07467 & 0.07467 & 0.07467 & 0.07467 \\
Inscribed Circle Diameter, & 78 & 78 & 78 & 78 & 78 \\
D & & & & & \\
Entry Angle, $\Phi$ & 60 & 60 & 60 & 60 & 60 \\
Entry Radius, r & 60 & 60 & 60 & 60 & 60 \\
M & 6.04965 & 6.04965 & 6.04965 & 6.04965 & 6.04965 \\
X & 7.60905 & 7.60905 & 7.60905 & 7.60905 & 7.60905 \\
tD & 1.07093 & 1.07093 & 1.07093 & 1.07093 & 1.07093 \\
fc & 0.56714 & 0.56714 & 0.56714 & 0.56714 & 0.56714 \\
F & 2305.5418 & 2305.5418 & 2305.5418 & 2305.5418 & 2305.5418 \\
K & 0.9285 & 0.9285 & 0.9285 & 0.9285 & 0.9285 \\
Qc & 1752 & 3821 & 4211 & 3932 & 6407 \\
Qe & 1218 & 128 & -77 & 70 & -1233 \\
\hline Sourc: from
\end{tabular}

Source: from study

From Table 6, it was realized that the Kejetia approach had the highest circulatory flow of $6407 \mathrm{pcu} / \mathrm{hr}$ at Airport roundabout. This meant that 6407 of the flow in the circulatory area was in conflict with the entry flow of -1233 . Airport approach had the lowest circulatory flow of $1752 \mathrm{pcu} / \mathrm{hr}$. This again meant that 1752 of the flow in the circulatory area was in conflict with the entry flow of 1218 .
The flow to capacity ratios of each approach at Airport Roundabout is shown in Table 7. 
Table -7: Flow to Capacity ratios at Airport Roundabout

\begin{tabular}{cccccc}
\hline Approaches & $\begin{array}{c}\text { Circulating } \\
\text { flow, Qc }\end{array}$ & $\begin{array}{c}\text { Entry } \\
\text { capacity } \\
\text { (pcu/hr) }\end{array}$ & $\begin{array}{c}\text { Entry flow } \\
(\mathbf{p c u} / \mathbf{h r})\end{array}$ & $\begin{array}{c}\text { Reserve } \\
\text { capacity } \\
(\boldsymbol{\%})\end{array}$ & $\begin{array}{c}\text { Flow to } \\
\text { capacity } \\
\text { ratio }\end{array}$ \\
\hline Anloga Jn & 4211 & -77 & 3238 & -166 & 2.66 \\
Krofrom & 3821 & 128 & 2683 & 3589 & -34.89 \\
Kejetia & 6407 & -1233 & 2180 & -1598 & 16.98 \\
Buokrom & 3932 & 70 & 2107 & -2893 & 29.93 \\
Airport & 1752 & 1218 & 173 & 114 & -0.14 \\
\hline
\end{tabular}

Source: from study

It was realized again from the capacity analysis that Airport roundabout was at full capacity based on the overall volume to capacity ratio as shown in Table 7. The above flow to capacity ratios revealed that Airport roundabout was operating at a level of service F. Level of service F described a forcedflow operation at low speeds, where volumes were below capacity. These conditions usually resulted from queues of vehicles backing up a restriction downstream at the roundabout. Speeds were reduced substantially and stoppages occurred for short or long periods of time because of the downstream congestion. It represented worst conditions.

\subsection{Intersection Capacity Analysis}

Performance of Airport roundabout after capacity analysis is shown in Table 8

Table 8: Performance of Airport roundabout

\begin{tabular}{lllll}
\hline Intersection & Control Type & v/c ratio & ICU \% & ICU LOS \\
\hline Airport Roundabout & Roundabout & 4.48 & 187.9 & $\mathrm{H}$ \\
\hline Source: from study & & & &
\end{tabular}

The result from Table 8 showed that Airport roundabout was performing beyond capacity in that, the roundabout was $9 \%$ or greater over capacity and was experiencing congestion over 2 hours per day.

\subsection{Signalization and Improvement of Airport}

\section{Roundabout}

The proposed Geometry for Airport Roundabout is shown in Fig.2. 


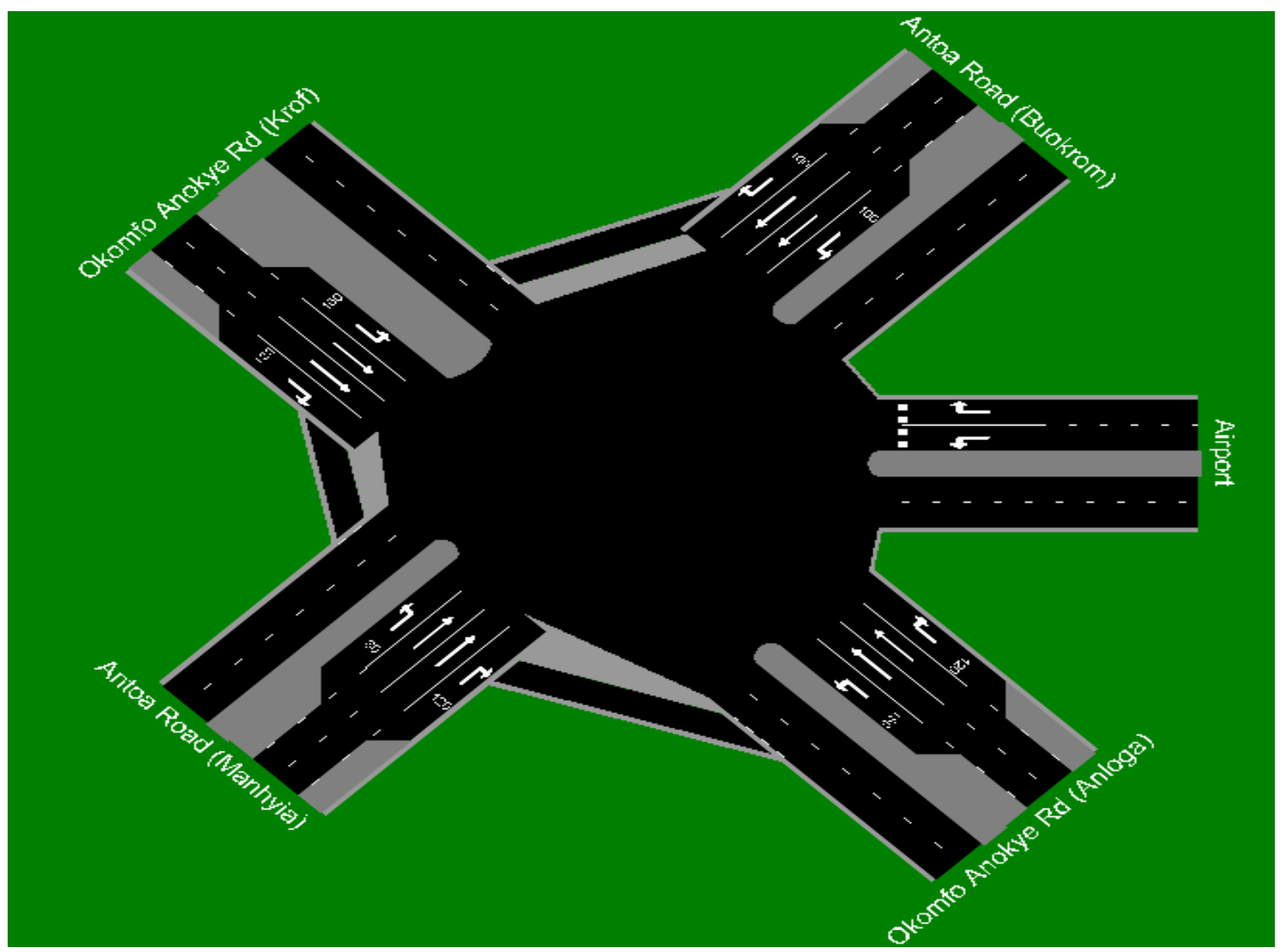

Fig 2: Proposed Geometry for Airport Roundabout; Source: from study

Signalized intersection with 4 approach lanes for the principal arterials was proposed as shown in Fig. 2. The Airport roundabout signalization was basically to improve on vehicular movement. However, signalization was proposed considering the non-availability of funds. By critical and careful examination of the conditions, signalization of the Airport roundabout was proposed to control all the movements. The proposed geometric data in Table 9 when implemented will improve upon the performance of the intersection. The central island would be channelized to aid motorists to move from one approach to the other in order to prevent conflicts and enhance safety. Pedestrian movements would be separated in order not to interrupt the flow by considering the number of lanes at each approach to the roundabout. A pedestrian footbridge was thus proposed on all legs to the roundabout. 
Table -9: Proposed Geometric Data for Airport Roundabout

\begin{tabular}{cccccccc}
\hline \multicolumn{7}{c}{ Intersection: Airport Roundabout } \\
\hline Movement & $\begin{array}{c}\text { From } \\
\text { (Area) }\end{array}$ & To (Area) & Veh/hr & $\begin{array}{c}\text { \% of } \\
\text { Heavy } \\
\text { vehicles }\end{array}$ & $\begin{array}{c}\text { No. of } \\
\text { Lanes }\end{array}$ & $\begin{array}{c}\text { Lane } \\
\text { width } \\
(\mathrm{m})\end{array}$ & $\begin{array}{c}\text { Storage } \\
\text { Length } \\
(\mathrm{m})\end{array}$ \\
NWBL & & Kejetia & 900 & 8 & 1 & 3.3 & 150.0 \\
NWBT & Anloga Jn & Krofrom & 1452 & 11 & 2 & 3.3 & \\
NWBR & & Buokrom & 860 & 7 & 1 & 4.8 & 120.0 \\
NWBR2 & & Airport & 26 & 0 & & & shared \\
SEBL & & Airport & 35 & 0 & 1 & 4.0 & 150.0 \\
SEBL2 & \multirow{2}{*}{ Krofrom } & Buokrom & 563 & 7 & & & shared \\
SEBT & & Anloga Jn & 1896 & 18 & 2 & 3.3 & \\
SEBR & & Kejetia & 189 & 12 & 1 & 4.8 & 120.0 \\
NEBL & & Krofrom & 198 & 9 & 1 & 4.0 & 80.0 \\
NEBT & \multirow{2}{*}{ Kejetia } & Buokrom & 960 & 17 & 2 & 3.3 & \\
NEBR & & Airport & 33 & 0 & 1 & 4.8 & 120.0 \\
NEBR2 & & Anloga Jn & 989 & 16 & & & shared \\
SWBL2 & & Airport & 13 & 0 & & & shared \\
SWBL & \multirow{2}{*}{ Buokrom } & Anloga Jn & 542 & 10 & 1 & 4.0 & 100.0 \\
SWBT & & Kejetia & 1230 & 17 & 2 & 3.3 & \\
SWBR & & Krofrom & 322 & 13 & 1 & 4.8 & 100.0 \\
WBL & & Kejetia & 49 & 0 & 1 & 3.4 & \\
WBL2 & \multirow{2}{*}{ Airport } & Anloga Jn & 65 & 0 & & & shared \\
WBR & & Krofrom & 36 & 0 & 1 & 3.4 & \\
WBR2 & & Buokrom & 23 & 0 & & & shared \\
\hline
\end{tabular}

Source: from study

\section{CONCLUSIONS}

Airport roundabout was performing at full capacity based on the overall volume to capacity ratio. Suame Roundabout should be signalized to control all the movements.

It is cheaper to implement the signalised intersection to control and alleviate vehicular movement than implementing the interchange. The central island should be channelized to enable motorists move from one approach to the other in order to prevent conflicts and enhance safety. A pedestrian footbridge should be constructed on all legs to the roundabout.

\section{ACKNOWLEDGEMENTS}

The authors would like to acknowledge the management of Kumasi Polytechnic, Kumasi headed by the Rector Prof. N.N.N. Nsowah-Nuamah, for providing financial assistance and also Department of Urban Roads (DUR), Kumasi for giving information on Airport roundabout in the Kumasi Metropolis. Several supports from staff of the Civil Engineering Department, Kumasi Polytechnic, Kumasi are well appreciated.

\section{REFERENCES}

[1]. FHWA. Roundabouts: An Informational Guide. Publication FHWA-RD-00-067 U.S. Department of Transportation, 2000

[2]. Oursten , L ., and Bared, J. 1995, Roundabouts: A Direct Way to Safer Highways. Public Roads, Vol. 58, No. 2, pp 4149.

[3]. Insurance Institute for Highway Safety, 2000, Status Report, Vol. 35, No. 5,. pp. 1-6.

[4]. Schoon, C., and van Minnen, J., 1994, The Safety of Roundabouts in the Netherlands. SWOV Institute for Road Safety Research, Traffic Engineering and Control

[5]. BCEOM and ACON Report (2004), Consultancy Services for Urban Transport Planning and Traffic Management Studies for Kumasi and Tamale for DUR (Ministry of Transportation, Ghana), Chapter 5, pp. 4-6, 8, 67, 86-87,117 [6]. Gerlough, D., and Huber, M. (1975) Traffic flow theory. A monograph. TRB Special Report 165. Washington, D.C. [7]. McDonald, M., Brackstone, M., and Sultan, B. (1998) Instrumented vehicle studies of traffic flow models. Proceedings of the Third International Symposium on Highway Capacity, Volume 2, Ryysgaard, R., ed., pp. 755- 
774. Copenhagen: Transportation Research Board and Danish Road Directorate.

[8]. Luo, L.H., Liu, H., Li, P., Wang, H., 2010. Model predictive control for adaptive cruise control with multiobjectives: comfort, fuel-economy, safety and car-following. Journal of Zhejiang University-SCIENCE A (Applied Physics and Engineering), 11(3):191-201. [doi:10.1631/jzus.A0900 374]

[9]. Tordeux, A., Lassarre, S., Roussignol, M., 2010. An adaptive time gap car following model. Transportation Research Part B: Methodological, 44(8-9):1115-1131. [doi:10. 1016/j.trb.2009.12.018]

[10]. Brackstone, M., McDonald, M., 1999. Car-following: a historical review. Transportation Research Part F, 2(4):181196.

[11]. Gazis, D.C., Herman, R., Rothery, R.W., 1961. Followthe leader models of traffic flow. Operations Research, 9(4):545-567. [doi:10.1287/opre.9.4.545]

[12]. Newell, G.F., 1961. Nonlinear effects in the dynamics of car following. Operations Research, 9(2):209-229.

[13]. Gipps, P.G., 1981. A behavioral car-following model for computer-simulation. Transportation Research Part B: Methodological, 15(2):105-111. [doi:10.1016/0191-2615 (81)90037-0]

[14]. Wiedemann, R., 1974. Simulation des Straß Enverkehrsflusses Schriftenreihe des Instituts für Verkehrswesen der Universität Karlsruhe (in German)

[15]. Kikuchi, C., Chakroborty, P., 1992. Car following model based on a fuzzy inference system. Transportation Research Record, 1365:82-91.

[16]. Wu, J.P., Brackstone, M., McDonald, M., 2000. Fuzzy sets and systems for a motorway microscopic simulation model. Fuzzy Sets and Systems, 116(1):65-76. [doi:10.1016/ S0165-0114(99)00038-X]

[17]. Gunay, B., 2007. Car following theory with lateral discomfort. Transportation Research Part B: Methodological, 41(7): 722-735. [doi:10.1016/j.trb.2007.02.002]

[18]. Mathew, T.V., Radhakrishnan, P., 2010. Calibration of micro simulation models for nonlane-based heterogeneous traffic at signalized intersections. Journal of Urban Planning and Development, 136(1):59-66. [doi:10.1061/ (ASCE)07339488(2010)136:1(59)]

[19]. Jin, S., Wang, D.H., Tao, P.F., Li, P.F., 2010. Non-lanebased full velocity difference car following model. Physica A: Statistical Mechanics and Its Applications, 389(21):46544662. [doi:10.1016/j.physa.2010.06.014

[20]. Husch, David "Intersection Capacity Utilization", Trafficware, 2003, accessed December 8, 2010.

\section{AUTHOR PROFILES}

Abena Obiri-Yeboah (Mrs) is a PhD Transportation Engineering Student at the Civil Engineering Department at the College of Engineering, KNUST-Kumasi. She holds an MSc. in Road and Transportation Engineering. Her research areas are Transportation and Highway Engineering, Traffic data Reduction and Analysis. She is a Member of Ghana Institution of Engineers (GhIE).

Emmanuel Kwesi Nyantakyi is a $\mathrm{PhD}$ Student at the Structural Geology Department, School of Earth Sciences, Yangtze University, Wuhan-China. He holds an MSc. in Road and Transportation Engineering. His research areas are Oil and Gas Storage and Transportation, Structural Geology, Seismic Interpretation and Geochemistry. He is a Member of American Association of Petroleum Geologists (AAPG).

Drussilla Pobee is a staff of the Civil Engineering Department, Kumasi Polytechnic and currently pursuing Master's in Water Resources Engineering. She holds an HND and BTech degree in Civil Engineering at Kumasi Polytechnic, Kumasi. Her research areas are Transportation Engineering, Water Supply and Highway Engineering.

Ghadafi Abdullai Mohammed is a staff of the Civil Engineering Department, Kumasi Polytechnic. He holds an HND and BTech degree in Civil Engineering at Kumasi Polytechnic. His research areas are Transportation Engineering, Water Supply and Highway Engineering. 